\title{
INTERCULTURALIDADE E ETNOSSABERES ${ }^{1}$
}

\section{JOSÉ GUILHERME DOS SANTOS FERNANDES ${ }^{2}$}

$U F P A$

RESUMO: Este artigo tem por objetivo apresentar o conceito de etnossaberes como alternativa integradora de outros conceitos referentes aos saberes de povos e comunidades tradicionais. Considerando essa discussão conceitual na educação superior, busca-se estabelecer parâmetros epistemológicos de aplicação do conceito de etnossaberes com base em Glissant (2005), Escobar (2012), Mato (2008 e 2014) e Fernandes e Fernandes (2015). A discussão tem como suporte documentos institucionais e estudo de realidades, a fim de se justificar, a partir da realidade brasileira, a necessidade da aplicação de referencial agregador de práticas e saberes oriundos de processos históricos colonialistas semelhantes.

PALAVRAS-CHAVE: educação superior; interculturalidade; etnossaberes; colonialismo.

ABSTRACT: This article aims to present the concept of ethnical knowledge as an integrating alternative of others concepts relating to traditional peoples and communities' knowledge. Considering this conceptual discussion in higher education, we seek to establish epistemological parameters to apply the concept of ethnical knowledge, based on Glissant (2005), Escobar (2012), Mato (2008, 2014) and Fernandes \& Fernandes (2015). The discussion is supported by institutional documents and study of realities in order to justify, from the Brazilian reality, the need to apply an aggregator framework of practices and knowledge derived from similar colonial historical processes.

KEYWORDS: higher education; interculturalism; ethnical knowledge; colonialism.

\footnotetext{
${ }^{1}$ Texto apresentado durante a $11^{\text {a }}$ Reunião de Antropologia do Mercosul, realizada em Montevidéu (Uruguai), entre 30 de novembro e 4 de dezembro de 2015, no GT 92 - Perspectivas sobre la interculturalidad en educación: experiencias formativas y procesos de identificación de indígenas y migrantes en contextos urbanos y rurales. Agradeço aos participantes do GT pela discussão e proposições, agora incorporadas ao texto.

${ }_{2}^{2}$ Professor associado da Universidade Federal do Pará (UFPA), mestre em Teoria Literária pela UFPA (1998), doutor em Literatura Brasileira pela Universidade Federal da Paraíba (2004) e pós-doutor em Colaboração Intercultural pela Universidad Nacional de Tres de Febrero (UNTREF, 2013). Vicecoordenador do Programa de Pós-Graduação em Linguagens e Saberes na Amazônia (UFPA), coordenador de pesquisas do Campus de Castanhal (UFPA), investigador pós-doutoral do Centro Interdisciplinar de Estudos Avançados (CIEA/UNTREF, Argentina). E-mail: mojuim@uol.com.br .
} 
A Organização Internacional do Trabalho (OIT), agência das Nações Unidas responsável por promover o acesso decente e produtivo de homens e mulheres ao trabalho, no ano de 1989 , em sua $76^{a}$ Conferência Internacional do Trabalho, estabeleceu a Convenção 169, que se configurou como o primeiro instrumento de reconhecimento dos direitos dos povos indígenas e tribais. Vale lembrar que este organismo, dedicado à formulação e à aplicação de normas internacionais do trabalho (convenções e recomendações), toma para si a responsabilidade de instituir diretrizes para os direitos trabalhistas de povos indígenas e tribais em razão da ancestral submissão destes povos como força de trabalho desde os domínios coloniais, em que seus direitos fundamentais foram desconsiderados. Mesmo na condição de ex-colônias, muitos países, como o Brasil e outros da América Latina, persistiram com o tratamento desigual dispensado a essas populações.

A Convenção aplica-se a povos e comunidades existentes em países independentes que são considerados indígenas em decorrência de já estarem fixados geograficamente por ocasião da conquista por estrangeiros ou no período da colonização por nações eurocêntricas, além de conservarem suas próprias instituições sociais, econômicas, culturais e políticas. Da mesma forma, reconhece-se a condição indígena a povos tribais que se distinguem de outros segmentos por apresentarem as mesmas instituições particulares acima. Tendo como fundamento a autoidentidade indígena ou tribal, em que nenhum Estado ou grupo social poderá negar o modo como determinado povo indígena ou tribal se reconhece e se designa, a Convenção 169 busca garantir a consulta e a participação desses povos na definição de prioridades de desenvolvimento que afetem suas crenças, instituições, valores, usos da terra e pertencimento ao seu território.

O Brasil somente ratifica a Convenção 169 em julho de 2002, treze anos após a sua instituição. Desde a presidência de José Sarney, quando da instituição da Convenção, até a presidência de Fernando Henrique Cardoso, quando da ratificação do instrumento pelo país, revezaram-se no governo da república quatro presidentes, mas somente com o sucessor deste último, Luiz Inácio Lula da Silva, em 2003, foi que efetivamente a Convenção 169 pôde influir efetivamente em políticas públicas para os povos indígenas e tribais. O que vem a ser um 
descalabro, justamente por se tratar de um país que apresenta um dos maiores números de línguas indígenas vivas - cerca de 150 , sendo superado neste aspecto somente por mais ou menos uma dúzia de países no mundo ${ }^{3}-$, mas onde somente a língua portuguesa é considerada oficial no país! $O$ fato se torna mais pesaroso se considerarmos que o Brasil é um dos membros fundadores da OIT, mantendo representação no organismo desde a década de 1950, sendo também um dos dez países com assento permanente em seu Conselho de Administração.

Com o governo Lula da Silva houve, por certo, avanços, que implicaram o fomento de políticas públicas para os povos e comunidades tradicionais, o que incluiu os indígenas e tribais referidos na Convenção 169. Um desses avanços é o Decreto 6.040/2007, que instituiu a Política Nacional de Desenvolvimento Sustentável dos Povos e Comunidades Tradicionais. Este decreto, em seu artigo $3^{\circ}$, define:

I - Povos e Comunidades Tradicionais: grupos culturalmente diferenciados e que se reconhecem como tais, que possuem formas próprias de organização social, que ocupam e usam territórios e recursos naturais como condição para sua reprodução cultural, social, religiosa, ancestral e econômica, utilizando conhecimentos, inovações e práticas gerados e transmitidos pela tradição;

II - Territórios Tradicionais: os espaços necessários a reprodução cultural, social e econômica dos povos e comunidades tradicionais, sejam eles utilizados de forma permanente ou temporária, observado, no que diz respeito aos povos indígenas e quilombolas, respectivamente, o que dispõem os arts. 231 da Constituição e 68 do Ato das Disposições Constitucionais Transitórias e demais regulamentações (BRASIL, decreto 6.040/2007, I-II).

Também como um outro avanço pode ser considerada a Lei $11.645 / 2008$, que altera a Lei 9.394, de 20 de dezembro de 1996, já modificada pela Lei 10.639 , de 9 de janeiro de 2003, e estabelece as diretrizes e bases da educação nacional, para incluir no currículo oficial da rede de ensino a obrigatoriedade da temática "História e Cultura

\footnotetext{
${ }^{3}$ Dados referenciados no site: http://saturno.museu-goeldi.br/lingmpeg/portal/?page_id=205. Acesso em $15 / 08 / 2015$.
} 
Afro-Brasileira e Indígena". Mais recentemente, o Conselho Nacional de Educação, no Parecer 06/2014, evocou Diretrizes Curriculares Nacionais para a Formação de Professores Indígenas, particularmente voltadas para os chamados cursos de licenciaturas interculturais. O parecer aponta alguns desafios no estabelecimento de parâmetros para o funcionamento desses cursos, dentre os quais gostaríamos de ressaltar: a simetria entre os diferentes saberes (indígenas e não indígenas); a aplicação de metodologias que considerem a interculturalidade crítica no diálogo entre diferentes "racionalidades" de compreensão do mundo; e o reconhecimento de diferenças em culturas postas em contato como valor precípuo para o estabelecimento do direito à igualdade. Ainda, o parecer torna explícita a preocupação de que a "formação de professores indígenas será específica, diferenciada, intercultural e, quando for o caso, bilíngue/multilíngue, em conformidade com os princípios da Educação Escolar Indígena".

Ademais, de acordo com a preocupação do Conselho Nacional de Educação (CNE), emanada no citado parecer, as instituições brasileiras de educação superior vêm oferecendo licenciaturas específicas para professores com atuação em territórios indígenas. A Universidade Estadual do Mato Grosso (UNEMAT) foi uma das pioneiras na instalação de cursos de ensino superior para a formação de professores indígenas, com a instalação do projeto de cursos de Licenciatura Específica para a Formação de Professores Indígenas, iniciado em 2001; juntamente com o Núcleo Insikiran, da Universidade Federal de Roraima (UFRR), que iniciou suas atividades em 2002, com o curso de Licenciatura Intercultural Indígena. Desde 1999, a formação específica tem sido objeto de apreciação e normatização, mediante as Diretrizes para o Funcionamento das Escolas Indígenas e das Diretrizes Curriculares Nacionais para a Educação Escolar Indígena na Educação Básica, definidas em 2012.

O que observo em toda essa discussão, iniciada em fins dos anos 90, do século XX, no Brasil, é que existem duas tendências para a efetivação dos princípios apontados desde a Convenção 169 da OIT, particularmente no que se refere aos artigos 27 e 28 desta convenção 4 .

\footnotetext{
${ }^{4}$ Os artigos referidos são enfáticos ao declararem que os programas e serviços educacionais destinados aos povos interessados devem satisfazer às necessidades destes, incorporando sua história, aspirações
} 
As instituições de ensino superior têm oscilado entre promover a inserção de atores de povos e comunidades tradicionais, mediante sistema de cotas, ou, de outro modo e recentemente, estimular a criação de cursos de licenciatura, notadamente, que tenham um projeto pedagógico acordado com os saberes ${ }^{5}$ e os fazeres desses povos. Em relação ao primeiro caso, já manifestei em artigo anterior minha opinião, que repito a seguir:

Por certo, existem experiências em universidades latino-americanas que se orientam aparentemente para a interculturalidade, mas de fato se limitam a oferecer programas de bolsas e cotas visando pequenos contingentes de indivíduos de populações indígenas e afrodescendentes, como meio de garantir o ingresso, aprimoramento acadêmico e progressão na academia. Essas iniciativas mais comuns não são sem valor, mas são unilaterais e não representam a colaboração entre diversas culturas; basicamente são iniciativas de inclusão de indivíduos indígenas e afrodescendentes em universidades "convencionais". Embora, em princípio, essas iniciativas, que garantem o acesso e a melhoria dos estudos de indivíduos indígenas e afrodescendentes, sejam valiosas, a médio e longo prazo não o são, porque não incorporam efetivamente o conhecimento proveniente da diversidade cultural (FERNANDES, 2014, p. 11-12).

Considero que a plena inserção intercultural não é somente a presença de atores nas instituições de ensino superior, mas a inclusão de seus saberes nos delineamentos curriculares, epistêmicos e metodológicos, pois entendo o conceito de interculturalidade como a colaboração solidária e criativa entre culturas em contato, com reconhecimento mútuo de seus valores e modos de vida (FERNANDES, 2014). Assim sendo, interessa-me, neste texto, a discussão e possíveis direcionamentos que apontem para além de passageiras "permissões" para que os atores historicamente postos à margem social e cultural frequentem as salas de aulas de instituições de educação superior. Daí a eleger-se o conceito de etnossaberes como mediador na construção de

econômicas, sociais e culturais. Também se afirma que os estados reconhecerão os direitos desses povos de criar suas próprias instituições e sistemas de educação, com vistas a transferir-lhes paulatinamente a execução.

${ }^{5}$ Para o conceito de saber aqui referenciado, ver Fernandes e Fernandes (2015). 
propostas educacionais mais relacionais e menos universais, como ontologia que poderá favorecer o diálogo de saberes no currículo e na prática pedagógica, em que as distintas percepções e práticas entre os atos do aprendizado não devem ter somente caráter valorativo, antes de tudo implicam em formas de apreensão e construção de realidades em perspectivas distintas e, por isso, têm diferentes situações de aplicabilidade, sejam em sociedades cosmopolitas ou sociedades aborígenes (FERNANDES e FERNANDES, 2015), mesmo que em certos momentos entrem em tensionamento.

No entanto, no Brasil, a grande gama de especificidades de ações inclusivas e propositivas em/de cursos de graduação - indígenas, quilombolas, etnodesenvolvimento, educação do campo - tem favorecido, de um lado, o reconhecimento da diversidade e da identidade, mas, de outro lado, impede-se a inter-relação destas tendências, que transitam entre a perspectiva antropológica, a pedagógica, a política e a sociológica, sem, contundo, promover-se o diálogo a fim de se reconhecer mais efetivamente a diversidade de atores e saberes vinculados a cada uma dessas ações inclusivas e propositivas, evitando-se, efetivamente, a realização da interculturalidade; este conceito, inclusive, está mais visceralmente ligado aos indígenas na realidade brasileira, indo de encontro à proposta de interculturalizar toda a educação superior (MATO, 2008). Como resultado, nas próprias universidades existem discursos e propostas que se desconhecem mutuamente. Para a realidade brasileira, acreditamos que o concepto de etnossaberes será um instrumento para o reconhecimento da diversidade a partir da unidade, indo-se ao encontro da concepção de Sumak Kawsay, ou bem-viver, de um bemestar de harmonia coletiva e horizontal da comunidade, em que todos os povos e comunidades tradicionais possam se compreender diferentes e ao mesmo tempo unidos por sua co-vivência, e perfeitamente aplicável aos processos educativos nacionais, em particular a educação superior:

Que la educación superior sea plenamente intercultural permite pensar el futuro desde otros valores y visiones de mundo, por ejemplo, en términos de "Buen Vivir", de manera coherente con visiones de mundo que entienden que los humanos somos parte de eso que en 
las sociedades occidentales modernas suele llamarse "Naturaleza", y no una especie pretendidamente superior que tiene el planeta a su servicio y lo visualiza y maneja como fuente de "Recursos Naturales". No es posible omitir que, unos pocos siglos de hegemonía de la cosmovisión occidental moderna nos han puesto ante desertificaciones, contaminación de las aguas, calentamiento global, $y$ otros desastres que aun estamos tratando de superar. Esto nos ha obligado a reconocer la estrechez de mira de la cosmovisión occidental moderna y sus potencialmente catastróficas consecuencias. Esas otras cosmogonías aún pueden ayudarnos a cambiar el rumbo. Esto hace al sustrato de las experiencias de educación superior que las organizaciones indígenas están impulsando (MATO, 2014, p. 23).

O conceito também poderá operacionalizar mais adequadamente a dificuldade em se propor uma referencialidade para os sistemas de reconhecimento e avaliação de instituições e programas inclusivos de povos e comunidades tradicionais, ao mesmo tempo "flexibilizando" e mantendo certa isonomia necessária à equidade de instituições tão diversas. Metodologicamente, esta é uma investigação de caráter documental, privilegiando-se os documentos de Estado e os diversos textos científicos que tratam da construção de identidade de povos e comunidades tradicionais, o que realizamos até o momento. Não descartaremos, no entanto, em certos momentos, a etnografia e a pesquisa participativa para entendermos melhor a lógica local, com o ajuste e adaptação do conceito a diferentes realidades.

\section{Da in-serção à con-fusão}

Em busca de garantir a diversidade cultural de povos e comunidades tradicionais na construção de políticas públicas sociais e na participação em instituições de estado, os governos de centroesquerda que se revezam desde 2003 no Brasil não atentaram para o fato de que, ao amainarem o caráter homogeneizante da globalização econômica e cultural, instituíram o que Hall classificou como a "proliferação subalterna da diferença": 
Juntamente com as tendências homogeneizantes da globalização, existe a "proliferação subalterna da diferença". Trata-se de um paradoxo da globalização contemporânea o fato de que, culturalmente, as coisas pareçam mais ou menos semelhantes entre si (um tipo de americanização da cultura global, por exemplo). Entretanto, concomitantemente, há a proliferação das "diferenças". O eixo "vertical" do poder cultural, econômico e tecnológico parece estar sempre marcado e compensado por conexões laterais, o que produz uma visão de mundo composta de muitas diferenças "locais", as quais o "global-vertical" é obrigado a considerar (HALL, 2003, p. 60).

Nada demais haver um cruzamento entre os interesses "globais" e as práticas "locais", em perspectiva multicultural e de compensação dos poderes "paralelos" em vista de um poder global, em conexões transversais e sobrepostas. Mas o ruído pode existir na primeira crise política e econômica, como a que ocorre no Brasil desde 2015, quando o cruzamento expôs outros interesses que objetivam o multiculturalismo liberal e comercial (HALL, 2003): no primeiro caso, busca-se a incorporação imediata de grupos culturais diversos na sociedade hegemônica, com vistas a uma cidadania individual universal, aceitando-se os localismos somente no domínio privado; no segundo caso, acredita-se que a minimização dos problemas oriundos da diferença cultural pode ser equacionada com o reconhecimento público dos grupos e a oferta de sua produção para o consumo privado, sem necessariamente haver redistribuição de poder e de recursos. Num caso e no outro, o resultado é a incompreensão de que, ao invés de criarmos guetos para público $A$ ou $B$, deveríamos criar políticas de inclusão de atores e seus saberes, em todos os espaços, sob o risco de apenas reforçarmos o distanciamento, diluindo a discussão urgente da formação do povo brasileiro. Além disso, o que a crise tem demonstrado é que qualquer discurso de apoio às "minorias" subalternas cai por terra frente às necessidades dos mercados globalizados, daí que, por pressão deste mercado, quando as agências de classificação de riscos econômicos impõem o rebaixamento do Brasil para o grau de mal pagador das dívidas públicas, de imediato os cortes para gerar recursos aos credores são realizados em políticas de inclusão social e de reconhecimento de práticas e saberes de povos e comunidades 
tradicionais. Vale lembrar que o corte no orçamento de 2015 para a educação foi de $19 \%$, totalizando um corte de $R \$ 9,4$ bilhões em relação ao orçamento total de $\mathrm{R} \$ 48,8$ bilhões.

O que essa compreensão da proliferação da diferença e do multiculturalismo nos oferece para a questão da inclusão de atores e de saberes na educação superior? De imediato, o reconhecimento de que a inserção destes não pode ser meramente pela garantia de nichos e guetos, pois o "simples" enlaçamento com os demais grupos já estabilizados e hegemônicos pode tão somente resultar, contrariamente a uma inserção, em uma "confusão" operacional e também de caráter cognitivo e epistemológico: lembremos que o vocábulo "confundir" significa reunir, misturar, a um ponto tal que torna as "coisas" em contato indistintas, como efeito da fricção que dissolve, ou seja, apaga as diferenças e as identidades. $E$ isso parece ocorrer nas políticas e iniciativas que têm utilizado o discurso das diferenças entre povos e comunidades para garantir nichos na academia, na conformação de cursos de graduação: educação do campo, etnodesenvolvimento, educação intercultural. Por isso defendo que, consequentemente ao fortalecimento de nichos, deve-se garantir a plena interculturalização da educação superior, isto é, a construção de um modelo de educação intercultural, o que será trabalhado com mais detalhe adiante.

A incoerência desses discursos isolacionistas está no fato de que procuram unicamente apontar as diferenças, sem atentarem que, se há diferenças, existe também o que os unifica. E esta questão é um dos problemas epistemológicos a ser considerado na configuração dos vários conceitos de inclusão de povos e comunidades tradicionais na educação superior, o que fica evidenciado em proposições das universidades. Tomemos como exemplo a Universidade Federal do Pará (UFPA), instituição da qual faço parte há pelo menos três décadas, desde a formação graduada até minha atual condição de professor, e na qual acompanhei o desenrolar das discussões acerca da política de acesso de povos e comunidades tradicionais à educação superior. A partir da Resolução 3.361/2005 - CONSEPE, estabeleceu-se que 50\%

\footnotetext{
${ }^{6}$ A UFPA é considerada uma das maiores universidades públicas da Amazônia brasileira, em termos de população universitária (59.842 pessoas) e em relação a orçamento executado ( $\mathrm{R} \$ 1.253 .888 .045,24)$, em dados de 2014.
} 
das vagas anuais da UFPA fossem destinadas a estudantes que tenham cursado todo o ensino médio em escolas públicas, e deste percentual destinou-se $40 \%$ aos que se autodeclarem negros ou pardos. Alguns cursos na instituição também garantem cotas de vagas para alunos autodeclarados indígenas, tanto na graduação como na pós-graduação. Evidentemente que deve haver, mais do que a autodeclaração, a certificação de pertencimento a uma comunidade étnica, respaldada por membros deste grupo, mediante suas lideranças. Aqui já se deslinda um primeiro problema, quando as lideranças comunitárias e étnicas, em causa própria e parental, distribuem declarações indiscriminadamente aos que não apresentam laços mais efetivos com o espaço ou grupo cultural, pois muitas vezes não são partícipes do ethos local, havendo uma diáspora que não replica, no local de moradia, as práticas e saberes do local de origem, mesmo porque essa origem é distante e silenciada, pela "vergonha ancestral"; o que fazer: ressignificar a cultura em novo local? Revisitar e incluir as práticas da modernidade-mundo? Tudo isso e mais uma nova mirada para a tradição? Entender tudo isso como uma atitude ludibriosa para com uma política séria social?

Mas para além das cotas, que incluem candidatos em vagas de cursos "convencionais" - o que não é o objetivo deste estudo -, existem, na UFPA, cursos voltados especificamente para essa população, a saber, a Licenciatura em Educação do Campo e a Licenciatura e o Bacharelado em Etnodesenvolvimento. O questionamento que eu faço é em relação ao nicho instituído para atender a populações que se encontram visceralmente ligadas em determinados aspectos, mas que se mantêm isoladas em razão de perspectivas acadêmicas e epistemológicas criadas unicamente desde a universidade: por que o distanciamento, e não a homologia? Vejamos inicialmente o que nos dizem os editais voltados para a seleção de candidatos em cada um dos cursos de graduação, ofertados em 2014. O curso de Licenciatura em Educação do Campo, divulgado mediante o Edital 06/2014 - COPERPS, na condição de processo seletivo especial, nos diz o seguinte:

O Curso de Licenciatura em Educação do Campo se destina a candidatos que atuam como Educadores do campo sem a qualificação de nível superior e a candidatos que vivem no campo e/ou pertencem a Comunidades do campo (COPERPS, 2014a, p. 1). 
E ainda complementa:

São consideradas Comunidades do Campo os grupos e populações organizados que habitam os espaços geográficos do campo (terra firme e várzea) e possuem relações sociais de vizinhança, parentesco, situação comum de interesses, identidade e formas de ação comum, ligados a esses espaços geográficos (COPERPS, 2014a, p. 1).

Em relação ao curso de Etnodesenvolvimento (Bacharelado e Licenciatura), o Edital 08/2014 - COPERPS, também na condição de processo seletivo especial, afirma o seguinte:

2.1.1. O Curso em Etnodesenvolvimento (Licenciatura e Bacharelado) é destinado a candidatos que pertencem a povos e comunidades tradicionais, nos termos de conceituação normativa definidos no Decreto $\mathrm{n}^{0}$. 6.040/2007 (Política Nacional de Desenvolvimento Sustentável de Povos e Comunidades Tradicionais) e na Convenção no. 169 da OIT.

2.2. Reserva de vagas para Comunidades Quilombolas para preenchimento de 2 (duas) vagas em cada Curso de Graduação que consta no item 3.1 deste Edital, em conformidade com a Resolução no. 4.309 de 27 de agosto de 2012 e mediante as condições estabelecidas neste edital.

2.3. Reserva de Vagas para Povos Indígenas para o preenchimento de 2 (duas) vagas em cada Curso de Graduação que consta no item 3.1 deste Edital, em conformidade com a Resolução no. 3.869 de 22 de junho de 2009 e mediante as condições estabelecidas neste edital (COPERPS, 2014b, p. 1).

O que se pode observar? Minimamente existe coincidência em relação ao público a que se destinam os editais. O edital 06/2014 anuncia que é destinado a candidatos que vivem no campo e/ou pertencem à comunidade do campo; esta, por sua vez, é caracterizada por grupos e populações que habitam no espaço geográfico do campo e mantêm relações parentais e comunais para alcançarem formas de ação comum ligadas ao espaço (trabalho?), à semelhança do que se classifica como povos e comunidades tradicionais em seus usos do território e recursos naturais a fim de garantir a reprodução cultural e econômica, 
segundo o Decreto 6.040/2007: trata-se dos mesmos grupos? E se caracteristicamente as comunidades do campo se aproximam das comunidades tradicionais, por que haver reserva de vagas para indígenas e quilombolas no edital 08/2014? Estes também não seriam próximos aos campesinos e aos comuneros ${ }^{7}$ tradicionais?

Vejamos alguns pontos de vista que podem nos auxiliar. Em primeiro lugar, busquemos semelhanças nas práticas e valores desses grupos. Tanto os campesinos como comuneros, quilombolas e indígenas têm sua existência vinculada à concepção de organização social como comunidade, considerada como a unidade no conjunto maior que é povo, ou seja, comunidade será considerada como a organização social adstrita a um determinado território (vila, aldeia, ou seja, ambientes antrópicos) em que o coletivo de indivíduos se relaciona por parentesco ou compadrio, respondendo pela forma mais embrionária na escala social mais complexa. Mantêm certa homogeneidade nas atividades econômicas e nos estados de pensamento (senso comum) e, ao mesmo tempo, apresentam relativa autossuficiência de amplo lastro para suas necessidades, além de consciência distintiva, que lhes garante uma identidade em grande parte coesa (RAPPORT e OVERING, 2000). Por isso, optei em reconhecer que os povos tradicionais incluem, para além de povos mestiçados ou afins caboclos, caiçaras, mulatos, etc. -, também os indígenas e afrodescendentes (quilombolas?), mesmo que os povos indígenas, por vezes, não sejam incluídos pelo termo populações tradicionais, em razão da distinção legal fundamental de que eles não são considerados no aspecto conservacionista, diferentemente dos demais. Por isso que, neste trabalho, não utilizamos o termo "populações" e sim povos ${ }^{8}$.

\footnotetext{
${ }^{7}$ Particularmente, considero que o termo comunero pode singularizar mais o indivíduo pertencente a povos e comunidades tradicionais, uma vez que aquele termo é mais substantivo e estes são mais adjetivos e coletivos. Em certas situações, comunero poderá referir-se ao coletivo sem a perda do caráter de pertença de que se reveste a expressão povos e comunidades tradicionais, como bem caracteriza o Dicionário Larousse: "el que tiene parte indivisa con otro u otros en un inmueble, un derecho, etc.; pueblos que tienen comunidad de pastos" (p. 174). E, considerando o que o Dicionário conceitua como comunidade, fica mais incisiva minha opinião de que comunero é o termo mais adequado para designar o participante de uma comunidade: "comunidad n.f. 2. Grupo social con intereses comunes. 3. Grupo de personas que viven en común para romper las bases egocéntricas de la pareja y de la familia, en los dominios afectivo y económico sobre todo" (p. 174).

${ }^{8}$ Ver em Fernandes e Fernandes: "o termo população tem um recorte de teor mais socioeconômico, pois se aplica em situações de relevância numérica (o quantitativo da população de um país). Por essa natureza mais genérica, o termo é utilizado com mais adequação ao conjunto de indivíduos de uma "mesma
} 
Desde estudo anterior, procuro relacionar a concepção de comunidade à de povo, pois, para que se compreenda que existem aproximações, e mesmo distanciamentos, entre indígenas, quilombolas e mestiços (do ponto de vista estritamente racial), há de se aceitar sua mais ampla designação como "povo", mesmo que na realidade brasileira reforce-se o separatismo, por vezes em deliberada ignorância recíproca, a despeito de uma história de aproximações e tensionamentos pela territorialidade comum, o que acredito ser fruto do "branqueamento" imposto pela história oficial colonialista, que afirma a formação tripartite do povo brasileiro em três caixas: branco, negro e índio. Se há essa formação inicial, por força mesmo da lógica branca, houve também as "misturas", na maioria das vezes bárbaras, mas que não podemos fechar os olhos ao fato de que a mestiçagem também existe. O que proclamo é que essa mestiçagem não seja compreendida unicamente pela via da democracia racial, o que é um descalabro que oculta o genocídio e as forçadas hibridações, mas que se entenda que o que resultou foi e é uma história processual, de frequentes plasticidades originadas dos contatos, às vezes com separações e conflitos, em outras com aproximações e criações 9 .

De todo modo, o conceito de povo tradicional, existente mediante comunidades, pode mediar melhor o que proponho como etnossaberes. Vejamos o que considero como povo:

o termo povo tem origem mais remota, do lat. popŭlus,i povo, multidão, conjunto de indivíduos que ocupa uma área territorial', o que denota o vínculo de coletivo a uma certa territorialidade, marcada por língua, história, costumes, interesses e tradições comuns, em uma palavra, uma identificação mais localizada, caracterização esta mais adequada ao conceito de povo tradicional. Não é demais dizer que o termo povo é mais adequado para o uso antropológico, visto seu teor de grupo étnico ou cultural, por mais que se deva ter o cuidado de distinguir camponeses

espécie" que ocupa uma área específica, o que denota a não qualificação da espécie ou mesmo a desconsideração da diversidade que possa haver nesse grupo. Por ter um apelo mais estatístico, população se vincula mais a uma ordem jurídica, por isso mais utilizado em investigação sociológica e na ciência política. Além de tudo, o termo tem origem mais recente, proveniente do latim medieval (populatı̌o,ōnis 'população, povo', de popǔlus,i 'povo'), quando se inicia a preocupação com a organização do Estado moderno, ou seja, advêm do termo povo" (FERNANDES e FERNANDES, 2015, p. 136).

${ }^{9}$ Vide o conceito de crioulização em Glissant (2005). 
(mestiços de toda ordem do campo e trabalhadores rurais) de indígenas, pelo fato de os primeiros manterem maior dependência com as cidades para sua reprodução social, econômica e cultural. Mas há de se perguntar: além de indígenas não contatados, como evitar um total isolamento em mundo globalizado? (FERNANDES e FERNANDES, 2015, p. 136-137).

O que chamo atenção na citação acima é que o que impõe o diferencial entre as faces de um mesmo povo - aqui considerado povo tradicional - é muito mais a ocupação territorial e a consequente organização social (cidade e campo) do que questões de ordem racial; estas são importantes sim, mas para frisar uma história de lutas e que são leit-motive do capital simbólico para conquistas atuais. No tocante a um modelo de sociedade sustentável e de construção para o bemviver, apanágio de um processo intercultural, creio que necessitamos, por vezes, proceder a aproximações em suas demandas, como no caso da educação superior, pois assim poderemos unificar forças em torno de lutas e conquistas comuns. Lutas muitas vezes desencadeadas pelo descompasso temporal entre valores próprios de um povo e a promoção da globalização econômica, sob a égide de um termo que se tornou tradução da sociedade moderna ocidental: desenvolvimento. Por isso, a proposição de um uma licenciatura em Etnodesenvolvimento, por mais que esteja pautada na Política Nacional de Desenvolvimento Sustentável de Povos e Comunidades Tradicionais, suscita dúvidas quanto à compreensão do termo desenvolvimento aliado às práticas e aos valores locais. Segundo Escobar (2012), desde o pós-Segunda Guerra Mundial, a doutrina Truman (1949), emanada pelo presidente Harry Truman dos Estados Unidos, estabeleceu as condições necessárias para a reprodução, em todo o mundo, do modo de vida das sociedades ditas avançadas, ou desenvolvidas, centradas em:

Altos niveles de industrialización y urbanización, tecnificación de la agricultura, rápido crecimiento de la producción material y los niveles de vida, y adaptación generalizada de la educación y los valores culturales modernos. En concepto de Truman, el capital, la ciencia y la tecnología eran los principales componentes que harían posible tal revolución masiva (ESCOBAR, 2012, p. 55). 
Nesse entendimento do mundo, "las filosofías ancestrales deben ser erradicadas; las viejas instituciones sociales tienen que desintegrarse" (UNITED NATIONS apud ESCOBAR, 2012, p. 56). O que não se percebeu de imediato foi que a maioria da população afetada por essa compreensão de um novo mundo não atestou a melhoria das condições de vida, mesmo perdendo seu vínculo ancestral com antepassados e com seus territórios, em razão da desenfreada busca pela urbanização e escolarização, ou seja, o desenvolvimento representou mais um discurso do que uma práxis, o que se reproduz até os dias de hoje. Ver o desenvolvimento como um discurso pode ajudar a compreender as razões pelas quais "desenvolver-se" passou a ser um problema existencial para os países colonizados na África, Américas e Ásia, assim como a análise dessa condição discursiva deve ser feita em termos dos regimes do discurso e de sua representação e confrontos: "los 'regímenes de representación' pueden analizarse como lugares de encuentro en los cuales las identidades se construyen pero donde también se origina, simboliza y maneja la violência" (ESCOBAR, 2012 , p. 63). Essa desintegração, proposta desde os anos 40 do século $\mathrm{XX}$, mais incisivamente, é reconhecida por algumas lideranças indígenas no Brasil, como Gersem Baniwa, indígena do Alto Rio Negro (AM) e professor da Universidade Federal do Amazonas. Durante sua participação no simpósio "Direitos indígenas: respeito ou violação?", coordenado pela Associação Brasileira de Antropologia, como parte da programação da $11^{\text {a }}$ Reunião de Antropologia do Mercosul, ocorrida de 30/11 a 4/12 de 2015, na cidade de Montevideo (Uruguai), declarou que para os "povos indígenas desenvolvimento tem sido sinônimo de problema, de violência, de desrespeito aos direitos, destruição de conhecimentos, destituição e negação de suas individualidades". $\mathrm{Na}$ oportunidade, sugeriu um outro conceito para desenvolvimento, nem um pouco próximo da doutrina Truman: "desenvolvimento é ter nossa terra (os indígenas) com saúde!".

Pelo exposto, tratar de desenvolvimento em práticas de povos tradicionais pode soar semitonado, mesmo que haja a preocupação de aliar o conceito de desenvolvimento ao diferencial sociocultural de uma sociedade, relativo à etnicidade. Ainda que se busque solucionar problemas locais mediante conhecimentos e tradições próprias, a 
existência de problemas em uma comunidade nem sempre é endêmica, podendo ser algo oriundo de condições assincrônicas do processo colonizador e "civilizatório", não havendo condições de conciliação entre causas, consequências e reversões do problema, por serem de ordem e valores diferenciados. Exemplo disso pode ser dado a um suposto caráter conservacionista de povos tradicionais: as comunidades tradicionais, particularmente os indígenas, são conservacionistas? Ora, o conceito de sustentabilidade é do mundo urbano, surgido sob o impacto do desenvolvimentismo em sua lógica econômica e de exploração da natureza. A vida comunitária mais tradicional é apegada a determinada territorialidade, organizada em parentesco e compadrio, com certa homogeneidade nas atividades econômicas e nos estados de pensamento (senso comum) e, por isso, apresenta relativa autossuficiência de amplo lastro para suas necessidades; frequentemente, causa baixo impacto ambiental, porque não possui grandes exigências de consumo: suas atividades são mais de sobrevivência (talvez sem maiores interesses na mais-valia, muito mais no capital simbólico endógeno), realizando-se em amplos espaços territoriais, em que habitam reduzido número de pessoas (tomemos como exemplo a região amazônica brasileira), em vilas e aldeias que variam de quinhentas a duas mil pessoas. Isso tudo aliado a uma forma de agir e representar sobre o mundo com tecnologia simplória, mas não menos complexa, e axiomas de uma cosmologia posta mediante um mundo paralelo e transversal, de seres míticos, em que a natureza é portal entre vivos e encantados, sem cair no clichê de povos "primitivos": lembremos que a mitologia é condição de todos os povos! Portanto, torna-se anafórico usar ipsis litteris um conceito gerado em outras condições que não as mesmas condições históricas e sociais de produção da vida. Daí a necessidade de conhecer in loco a realidade de povos e comunidades para proceder-se à releitura e ressignificação de conceitos e práticas oriundas da vida urbana e científica, quando os mundos diversos são postos em contato.

Mas nem sempre é o que ocorre em iniciativas que se consideram interculturais. Observei a questão em proposição de curso de licenciatura intercultural indígena da Universidade do Estado do Pará, em que as formações de professores do curso, mesmo a despeito de 
privilegiarem a pesquisa como fator dinamizador da aprendizagem, não priorizaram a etnografia e a história oral em trabalhos de campo; no máximo, o contato com a aldeia deu-se mediante os relatos dos alunos, como podemos ver abaixo:

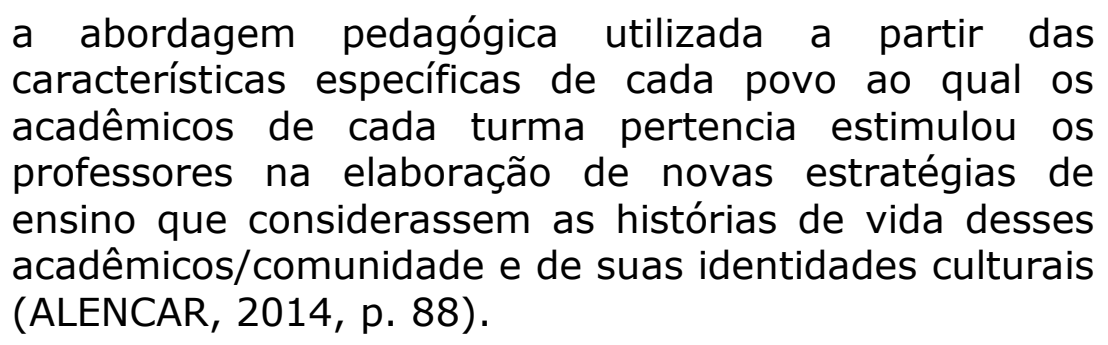

Entendo pela necessidade de maior frequência em contatos de alternância, o tempo-escola e o tempo-aldeia, talvez privilegiando mais este, uma vez que, nessa metodologia semipresencial, ou de alternância, há um período de estudos no espaço de formação acadêmico e outro período de atividades nos espaços de origem dos indígenas, momento este em que há um diagnóstico sobre a comunidade e a escola, com posterior problematização da realidade e a elaboração de proposta pedagógica e de intervenção; realiza-se a execução da proposta e finaliza-se o estudo com reflexão e conclusão, o que se configura como trabalho final do curso. Além do mais, o caráter epistemológico do saber tradicional parte do diálogo de saberes; assim, nesse diálogo,

há de se considerar que os saberes estão em contexto, ou seja, nesse diálogo é importante o sentir-pensarfazer. Por isso, deve-se atentar para uma educação dos sentidos, de envolvimento do corpo, em atitude participativa e solidária, pois o aprendizado de alguns saberes se dá de forma coletiva, em visão holística (FERNANDES, 2014, p. 28).

O privilégio da participação em formações de professores, sem a presença de atores mais locais, pode enviesar a compreensão da cultura do outro, em momentos de tensão tradutória, pois existem limites para a tradução entre culturas, quando o processo intercultural requer que saibamos que há elemento intracultural em cada saber isolado e posto em contato, que é parte da estrutura do pensamento do grupo social, e isso, muitas vezes, é intraduzível para outro grupo social: daí o sentir- 
pensar-fazer como recurso da experiência ímpar que é descobrir o sentir/sentido da cultura a que somos postos em contato.

Em um balanço geral sobre a questão, creio que, mesmo que existam equívocos e incompreensões acerca da interculturalidade, as iniciativas até então realizadas, nas realidades sob meu foco, não deixam de ter validade, nem que seja minimamente por trazerem propostas de inclusão de saberes e não apenas de sujeitos (do contrário, muitas vezes se tornam assujeitados pelas práticas das universidades convencionais). O que proclamo, de imediato, é pela necessidade de tecermos pontos de contato entre as concepções, sob o risco de, ao invés de incluirmos, realizarmos exclusões e separatismo, que podem provocar mais facilmente o controle e reificar o domínio das classes hegemônicas, por gerar a guetoização dos subalternos: ao dar pão e circo, ou a ilusão da inclusão de atores no ensino superior, alienase estes atores de uma compreensão de mundo relacional e que preserve suas especificidades, afinal, eu reconhecer-me como portador de uma identidade ocorre pelas identificações que ao longo dos contatos adquire-se, daí que estar-com-o-outro seja uma necessidade para a construção de meus pertencimentos. Balée trata esse processo como "indigeneidade", e que compreendo expansivamente como vinculado aos modos ser de povos e comunidades tradicionais:

Indigeneity is the sense of belonging to some specific place and being someone who is native or aboriginal, a descendant of the first people to live in the place considered to be a homeland. Indigenous people have an ethnicity that is distinctive; they are culturally unlike the dominant, mainstream society in which they live and often exist in subaltern (that is, not dominant) enclaves, either in the place of origin or where they have ended up in diasporas. A sense of indigeneity may involve use of an identifying term in order to establish a distinct identity relative to the rest of society (BALÉE, 2012, p. 253).

Na compreensão do autor, o ser indígena, ou "indigeneidade", não difere das considerações sobre o ser povo e/ou comunidade tradicional, em minha concepção. Porque existe o reconhecimento da diferença em relação ao outro, o dominante ou restante da sociedade, diferença marcada pela etnicidade, descendência e território distinto, a homeland. 
E mais adiante, na obra, Balée assevera que as condições marcadas da diferença têm dois movimentos: um segmental, de autorreconhecimento de indivíduos do pertencimento a grupo social distinto; e outro relacional, em função da interação de costumes do grupo com o estadonacional. Aceitar-se a dinâmica própria das culturas, como desde sempre postas em movimentos e contatos, interações e repulsões, ajuda a pensar em uma saída que seja um constructo alternativo ao procedimento de vanguarda, na construção do diferencial como autônomo, o que é legítimo em um primeiro momento de revolução; mas como transformação, o passo seguinte é compreender que as vanguardas também constroem relações para que possam se retroalimentar e manterem-se hegemonicamente: é próprio das relações sociais. Portanto, há a necessidade de um conceito que se remeta ao estágio das transformações, desenvolvidas desde os contatos interculturais, daí o relevo pelo conceito de Etnossaberes, a ser tratado amiúde a seguir.

\section{Interculturalizar a sociedade e a academia: caminho de etnossaberes}

Interculturalidade é o contato entre culturas, com possíveis trocas que se estabelecem em termos equitativos e em condições de igualdade, como processo de permanente relação, comunicação e aprendizagem entre pessoas, grupos, conhecimentos, valores e tradições, sem necessariamente haver a fusão, ou hibridização, entre as práticas e os saberes postos em contato. Dito isto, entende-se, aqui, que o conceito de etnossaberes, com acento na pluralidade dos mesmos, pressupõe uma forma de contato - pelo conjunto mais amplo de contatos, responderia a interculturalidade - em que diferentes formas de agir sobre o mundo estão pautadas em diferentes formas de pensar, mas que podem ter pontos de contato, dada a natureza unitária das necessidades biofisiológicas humanas, mas que originam diversas soluções culturais, dado o caráter amplo e multifacetado das ações humanas na natureza, pelo viés da adaptabilidade das culturas. Ir ao encontro e de encontro com o Diverso (aquele que é o Outro em relação a mim, ao Mesmo), inicialmente, e entender suas lógicas de produção e 
reprodução, assim como suas relações internas e com outros diversos, é um primeiro movimento, que por certo gera a identidade e o sentido de localismo e independência; posteriormente, creio ser pertinente o encontro de pontos de contato, seja pelo estabelecimento de homologias na construção de saberes aparentemente distintos, ou por haver história de contatos, com logros e perdas, semelhantes, a exemplo de processos de colonização próximos. Exemplo deste caso são as aproximações entre povos indígenas e quilombolas na região do Vale do Rio Gurupi, entre Pará e Maranhão, que, se proporcionaram guerras e distanciamentos, geraram também misturas, como nos diz Darcy Ribeiro, quando de sua pesquisa etnográfica na região, particularmente nas comunidades quilombolas de Camiranga e Itamoari, pelos idos de 1949-1950: "A população muito misturada. Há quase tantos caboclos quanto negros, que vão se misturando com entusiasmo. Caboclo aqui é a gente local reconhecidamente não indígena, nem negra" (1996, p. 51). E complementa:

O único bicho que se multiplicou na calha do rio foi gente, principalmente negros fugidos da escravidão, que foi numerosa no Maranhão, e concentrados em vários quilombos, que acabaram se juntando aqui como mão-de-obra das explorações de ouro. Há também boa quantidade de caboclos. São mulatos e mestiços paridos principalmente por mulheres indígenas retiradas das aldeias e fecundadas por brancos e negros. Seus filhos nasceram soltos, deserdados da cultura índia e da negra, misturando elementos das duas com a europeia (RIBEIRO, 1996, p. 70).

Pode-se observar que a compreensão das culturas do Gurupi unicamente pela matricialidade tripartite - brancos, negros, índios - não dá conta dos processos violentos e amalgamados na região, que, se proporcionaram a leitura de resistência dos quilombolas e a (re)construção de uma identidade própria, que implicou no reconhecimento da comunidade de Camiranga, pelo governo estadual do Pará, como quilombola, com todos os direitos, frutos de luta histórica e política, pode, de outro modo, enterrar as nuanças de uma história pautada muito além de grupos individualizados e sem relações com os demais. Entender-se unicamente esta versão é não reconhecer 
que houve invasões tanto de brancos quanto de negros, por ocasião da febre aurífera no início do século XX, às aldeias dos indígenas ka'ápor, para sequestro de mulheres, uma vez que tanto os brancos quanto os negros foram para a região despossuídos de famílias e companhias femininas. Uns pelo ofício de desbravador mineiro, outros pelas circunstâncias de fuga, condição, na maioria das vezes, dos homens, que deixavam filhos e mulheres nas cidades, a exemplo de Bragança (PA), onde a herança dessa condição está presente na festa da Marujada de São Benedito, festa eminentemente matriarcal, tocada pela irmandade de mesmo nome.

Portanto, se existe a necessidade de se afirmar a identidade raiz, pautada em visão atávica da cultura de origem, existe também as culturas compósitas, oriundas de um processo contínuo de crioulização. E o que vem a ser crioulização? Segundo Glissant, autor martinicano criador do mesmo, implica em processo de desterritorialização, desaculturação e ressignificação sofridos pelas várias etnias negras, vindas nos navios negreiros e lançadas às plantações como escravos, com línguas e hábitos diferentes, sendo estas etnias despojadas de todos os elementos de suas práticas e saberes cotidianos, e principalmente de sua língua:

O que aconteceu com esse migrante? Ele recompõe, através de rastros/resíduos, uma língua e manifestações artísticas, que poderíamos dizer válidas para todos (...). O pensamento do rastro/resíduo me parece constituir uma dimensão nova daquilo que é necessário opormos, na situação atual do mundo, ao que chamo de pensamentos de sistema ou sistemas de pensamento. Os pensamentos de sistema ou os sistemas de pensamento foram prodigiosamente fecundos, prodigiosamente conquistadores e prodigiosamente mortais. $O$ pensamento do rastro/resíduo é aquele que se aplica, em nossos dias, da forma mais válida, à falsa universalidade dos pensamentos de sistema (GLISSANT, 2005, p. 19-20).

Baseado em Glissant é que quero entender os etnossaberes como processuais e relacionais, em que cabe o monolítico pensamento de sistema sim, mas naquilo que ele pode oferecer como possibilidade de desconstrução de si próprio, justamente por estar em relação de 
oposição e complementação com os demais sistemas de pensamento, com os quais poderá constituir um pensamento de rastro/resíduo. Mas por causa do estacionamento em sistemas fechados por alguns militantes-pensadores de causas particularizadas, favorecido por uma visão de nicho para certos povos e comunidades tradicionais, desconhece-se, ou se quer desconhecer, a vizinhança conceitual gestada em interações históricas e sociais, a exemplo do que ocorreu no Gurupi, pois não se quer dividir o quintal. Exemplo disso é a redação da Lei 10.639/2003, que alterou a Lei 9,394/1996; aquela, por seu turno, foi alterada pela Lei $11.645 / 2008$. A lei de 2003 diz o seguinte, em seu artigo $1^{\circ}$ :

A Lei no 9.394, de 20 de dezembro de 1996, passa a vigorar acrescida dos seguintes arts. 26-A, 79-A e 79B:

Art. 26-A. Nos estabelecimentos de ensino fundamental e médio, oficiais e particulares, torna-se obrigatório o ensino sobre História e Cultura Afro-Brasileira.

A Lei 11.645/2008 mantém basicamente o mesmo texto, relativo ao artigo $1^{\circ}$, sendo acrescido: "torna-se obrigatório o ensino sobre história e cultura afro-brasileira e indígena" (grifo meu). Essa pequena alteração, em meu entendimento, tem gerado controvérsias, uma vez que determinados segmentos do movimento negro simplesmente não consideram a lei de 2008 em seus discursos, unicamente se referindo à lei de 2003 quando tratam de invocar a necessidade de implementação de ensino de relações étnico-raciais na educação básica. Ora, no próprio site do governo federal (http://www.planalto.gov.br/ccivil_03/LEIS/L9394.htm), a redação de 2003 já aparece como inválida; então por que não se proclamar a dualidade da lei para fins de reconhecimento do silenciamento de povos massacrados pelos mesmos atores colonialistas? Algumas justificativas, na esfera dos pedagogos militantes de plantão, dizem respeito a que a lei não está regulamentada pelo Ministério da Educação para que se tenha uma abordagem conjunta ou a preparação de material didático que contemple aos indígenas; mas pergunto: burocratizar a história para quê? O fato existe e é tudo, explica-se por si mesmo, como visto nos contatos culturais no Vale do Rio Gurupi. 
Talvez para minimizar esse "desconhecimento", a crioulização dê uma resposta mais palatável:

A crioulização supõe que, os elementos culturais colocados em presença uns dos outros devam ser obrigatoriamente "equivalentes em valor" para que essa crioulização se efetue realmente. Isso significa que se nos elementos culturais colocados em relação, alguns são inferiorizados em relação a outros, a crioulização não se dá verdadeiramente (GLISSANT, 2005, p. 21).

Reconhecer-se a partir do outro a mim me parece a "ontologia da identidade" enquanto processo, e em seus desdobramentos nas identificações. A partir desta compreensão, será possível propor de fato a interculturalidade para todos:

a interculturalidade deve ser trabalhada por todos os atores sociais, se realmente queremos que seja uma característica da sociedade como um todo em seu processo de construção democrática. A perspectiva da interculturalidade crítica acentua esta busca e procura trabalhá-la a partir dos seus pressupostos (CANDAU, 2009, p. 5).

Mas a autora reconhece que, de momento, na América Latina, não se tem avançado muito além de uma interculturalidade funcional, que privilegia exclusivamente grupos subalternizados, principalmente indígenas e, por vezes, afrodescendentes. A questão do atravancamento é que na região existe muito preconceito racial velado, mascarado pelo discurso de defesa da coesão social e nacional, o que impede que se aceite a inclusão de aspectos socioculturais no currículo escolar, mantendo a hegemonia do eurocentrismo, com pitadas de lógica estadunidense.

Por sinal, a manutenção dessa condição colonialista é reflexo da incapacidade de nossos ancestrais colonizadores, agora representados pelas lideranças crioulas nativistas, presentes na sociedade burguesa e na academia locais, resolverem dois problemas centrais suscitados pelo funcionamento dessa "civilização":

Le fait est que la civilisation dite «européene», la civilisation «occidentale», telle que l'ont façonnée deux 
siècles de régime bourgeois, est incapable de résoudre les deux problèmes majeurs auxquels son existence a donné naissance: le problème du prolètariat et le problème colonial (CÉSAIRE, 2004, p. 7).

Como são incapazes de extirpar o colonialismo e o proletariado, duas faces geradas pela mesma incompreensão do Outro, visto unicamente como o selvagem e não desenvolvido, a solução é manterse as condições de reprodução, em que dividir os grupos é a melhor estratégia para dominá-los, segregando-os em seus guetos e reforçando o desconhecimento recíproco, por falaram "línguas" diversas, assim como faziam os senhores nos navios negreiros.

Mas quero crer que, mesmo sendo acusado de querer minimizar e aplainar as diferenças, o reconhecimento de histórias e identificações cercanas, de povos em contato pelo processo colonizador, não impede que tenhamos a compreensão de particularidades, pois a aplicação do conceito de etnossaberes para aproximar povos e comunidades tradicionais em perspectiva de serem usuários de práticas e saberes próximos oportuniza a tradução cultural, e toda tradução sempre se refere a complexos processos epistemológicos, em que as disposições interculturais e interepistêmicas são necessárias para que haja ontologias múltiplas, sendo a garantia da transição a uma compreensão moderna do mundo como um pluriverso e não um universo. Por isso, entender os etnossaberes é deslindar a história sociocultural dos objetos e de suas percepções e representações em cada cultura, e entre as culturas postas em contato. Deve-se entender que cada episteme é um paradigma de saber estruturado conforme a época e o grupo social, mesmo a despeito de haver características (formas e matérias) "universais" nos objetos.

Por fim, vale dizer que o que me move a toda essa discussão epistêmica é a possibilidade de, ao reconceituar certos procedimentos na e para a sociedade brasileira, possa favorecer, senão a uma efetiva discussão, pelo menos a desacomodação de possíveis "verdades" irrefutáveis, pois creio ser este o princípio para avanços mais determinantes, que evitem ser imperativos globais. Apraz-me a ideia do bem-viver, mas sigo com a opinião do economista equatoriano Alberto Acosta, ministro de Minas e Energia entre 2007 e 2008, que, em 
entrevista à repórter Marsílea Gombata (26/01/2016), do Opera Mundi, disse, em consideração ao conceito de Sumak Kawsay:

Quando falamos do bem viver estamos falando de construir uma vida em harmonia entre os seres humanos, vivendo em comunidade, com seus semelhantes e a natureza. Estamos falando de bons conviveres, ou seja, entre os seres humanos na comunidade, entre comunidades e entre indivíduos, comunidades e natureza. O bem viver, o sumak kawsay que emerge do mundo indígena, distancia-se de conceitos ocidentais que concebem o surgimento da vida política a partir de uma ruptura em relação à natureza. Dessa perspectiva, a tarefa é abrir a porta a transições que nos permitam construir outras formas de vida diferentes das atualmente dominantes (ACOSTA apud GOMBATA, 2016, n.p.).

E por que não nos darmos essa oportunidade de transformar coletivamente nossa forma ocidental, colonialista e proletária de existência? Tudo começa por nos fazermos ver, e ver-nos pelo Outro, com mirada intercultural que nos aponte os etnossaberes.

\section{Referências bibliográficas}

ALENCAR, Joelma Cristina Parente Monteiro. Educação intercultural e a formação específica de professores indígenas no ensino superior. Revista Fórum Identidades, Itabaiana, v. 8, n. 16, p. 79-98, 2014.

BALÉE, William. Inside cultures: a new introduction to cultural anthropology. Walnut Creek, CA: Left Coast Press, 2012.

BEZERRA NETO, José Maia. Escravidão negra no Pará. Belém: Paka-Tatu, 2012.

CANDAU, Vera Maria. Educação intercultural na América Latina: tensões atuais. In: Congresso Iberoamericano de História da Educação na América Latina (CIHELA). Rio de Janeiro: UERJ, 2009. Disponível em: http://www.gecec.pro.br/downloads/03_Edu_Intercultural_na_AL.pdf. Acesso em 08/02/2016. Acesso em: 26 dez. 2016.

CÉSAIRE, Aimé. Discours sur le colonialisme. Paris: Présence Africaine, 2004.

COPERPS. Edital 06/2014. 2014a. 
Edital 08/2014. 2014b.

ESCOBAR, Arturo. La invención del desarrollo. Cauca: Editorial Universidad del Cauca, 2012.

FERNANDES, José Guilherme dos Santos. Colaboração intercultural na educação superior: conflitos e negociações em experiências na Argentina, no Brasil, na Colômbia e no Peru. Espaço Ameríndio, Porto Alegre, v. 8, n. 1, p. 10-39, jan./jun. 2014.

FERNANDES, José Guilherme dos Santos; FERNANDES, Daniel dos Santos. A 'experiência próxima': saber e conhecimento em povos tradicionais. Espaço Ameríndio, Porto Alegre, v. 9, n. 1, p. 127-150, jan./jun. 2015.

FIORIN, José Luiz. Em busca do sentido: estudos discursivos. São Paulo: Companhia das Letras, 2012.

GLISSANT, Édouard. Introdução à uma poética da diversidade. Juiz de Fora: Editora UFJF, 2005.

GOMBATA, Marsílea. Governos progressistas da AL seguem atados à lógica de exploração da natureza, diz ex-ministro de Correa. In: Opera mundi. São Paulo: UOL, $2016 . \quad$ Disponível em: http://operamundi.uol.com.br/conteudo/entrevistas/43030/governos+progressistas+da+a 1+seguem+atados+a+logica+de+exploracao+da+natureza+diz+ex-

ministro+de+correa.shtml\#. Acesso em: 08 fev. 2016.

HALL, Stuart. Da diáspora: identidades e mediações culturais. Belo Horizonte/Brasília: Ed. UFMG/UNESCO, 2003.

LAROUSSE: diccionario enciclopédico usual. México, DF: Ediciones Larousse, 2008.

MATO, Daniel. No hay saber 'universal', la colaboración intercultural es imprescindible. In: Alteridades. Cidade do México, 2008. p. 101-116.

MATO, Daniel. Universidades indígenas en América Latina. Principales características, logros, problemas y desafíos. Revista Inclusión Social y Equidad en la Educación Superior (ISEES), Santiago de Chile, n. 14, p. 63-85, 2014.

RAPPORT, Nigel; OVERING, Joanna. Social and cultural anthropology: the key concepts. London: Routledge, 2000.

RIBEIRO, Darcy. Diários índios: os Urubus-Kaapor. São Paulo: Companhia das Letras, 1996. 
José Guilherme Dos Santos Fernandes - INTERCULTURALIDADE E ETNOSSABERES

Recebido em: 13/02/2016* Aprovado em: 21/06/2016 * Publicado em: 31/12/2016

Espaço Ameríndio, Porto Alegre, v. 10, n. 2, p. 39-65, jul./dez. 2016. 